phonate, although the tube was supposed to be in the larynx; difficulty in extraction by means of the string confirmed his diagnosis. Stenosis of the larynx, partial or complete, is recorded by Mr. Pitts and Dr. Brook, Dr. Basan, Dr. Chavasse, ${ }^{22}$ and Widerhoffer. ${ }^{23}$ Dr. Mackenzie gives a case of abscess over the front of the larynx. I have seen a non-diphtheritic case in which an abscess gradually developed over the front of the trachea, although the tube had only been in use for 18 hours. The abscess extended from the cricoid to the thymus gland. Swallowing of the tube has occurred in the practice of several writers. The tube is always passed without trouble. In a case of undiagnosed retro-œesophageal abscess two tubes, of different sizes, were used. At the post-mortem examination two excoriated patches were found on the anterior tracheal wall corresponding to the lower ends of the two tubes. The tubes were both in use for 24 hours. Some excoriation was present in the centre of the posterior surface of the epiglottis. The voice does not seem to be altered for any length of time after intubation. Speech rapidly becomes distinct, though some huskiness may remain for several days or even weeks. In two cases, intubated for three and four days respectively, the voice was still weak three weeks after removal of the tabe. The chances of permanently damaging the larynx are small indeed. The boy who required the tube for 35 days (Case 4) recovered the use of his voice completely.

In conclusion, I may state that nearly all the above cases were proved to be diphtherial in origin by bacteriological examination and that in each of the cases in which such examination gave negative results definite membrane was discharged from the larynx or trachea. In this country sufficient attention has not been given to intubation. Its employment in a few more hospitals would, I think, eventually lead to its adoption in all.

Harley-street, $W$.

\section{TWO FATAL CASES OF PARTIAL THYROIDECTOMY,}

DEATH RESULTING IN ONE CASE FROM INSUFFICIENCY OF THYROID SECRETION AND IN THE OTHER FROM ITS EXCESSIVE ABSORPTION.

BY FRANK COLE MADDEN, M.B., B.S. MELB., F. R.C.S. ENG.,

PROFESSOR OF SURGERY AT THE EGYPTIAN GOVERNMENT SCHOOT OF MEDICINE; SENIOR SURGEON TO THE KASR-EL-AINI HOSPITAI, CATRO.

GorTRE is a very common condition in Egypt and usually has attained such a size before advice is sought that partial removal holds out the only hope of relief from the symptoms which, however, in almost all cases are those of inconvenience from the great size of the tumour and not of injurious pressure upon the trachea, the veins and nerves of the neck, or any other important structures. In spite of the difficulties 'and dangers of the operation, such as hæmorrhage, interference with the vagus nerve, \&c., the patients usually do well and only very rarely exhibit any untoward post-operative. complications. The cases which I wish to record are very good illustrations of the possible complications of the operation, depending entirely upon the condition in which the thyroid gland is left after it.

OASE 1.-The first patient was an Egyptian girl, aged 12 years, who was a deaf-mute but who in other respects appeared to be quite intelligent and well developed. As is unfortunately only too common with Egyptians of even average intelligence, no satisfactory history as to the duration and rate of growth of the tumour could be obtained, the only relative of the patient living at a great distance from Oairo. From an examination of the illustration (Fig. 1) it will be seen that the appearances were those of a typical tri-lobed goitre, which was not adherent either to the skin or to the deep structures of the neck. There was no dyspncea or dysphagia or other sign of pressure, but all the movements of the neck were considerably interfered with owing to the size of the goitre.

The removal of the mass after the skin of the front of the neck had been raised in one large apron-shaped flap presented no special difficulty ; indeed, it was so easy to shell out all three lobes that I was much tempted to remove them entirely. However, a piece of the isthmus of the size of a walnut was left in the middle line of the neck, and after careful ligature of all the divided vessels the skin flap was sutured with a continuous silk suture and the whole wound was thus closed without drainage. Two days after the operation the patient had a sudden attack of dyspncea and presented all the symptoms of severe laryngeal spasm. The spasm subsided after a few hours and did not recur until many days later. On the following morning all the signs of early and not very marked tetany were observed in the hands and feet and a thyroid tabloid of five grains was

FIG. 1.

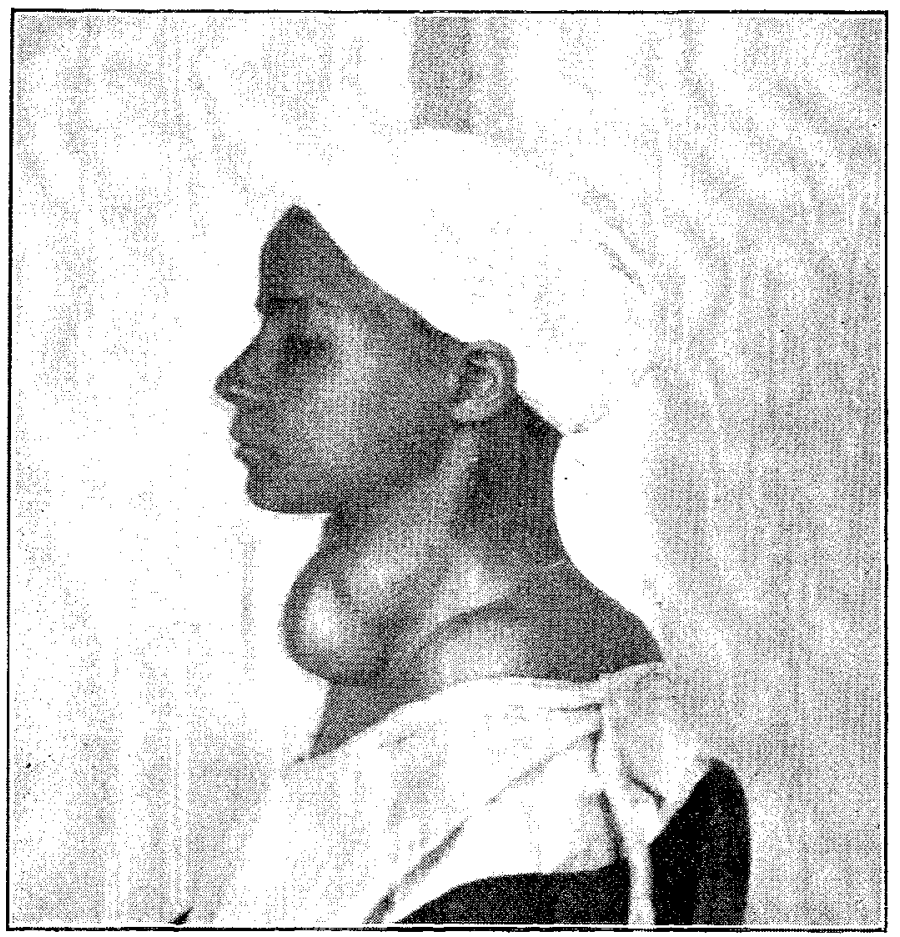

Showing multiple-lobed goitre,

ordered to be given twice a day. During the next two days the tetany persisted and became much more marked and then it gradually disappeared.

It was noticed that the patient had become very pale and anæmic since the operation, but there was no sign of myxœdema anywhere, either at this time or subsequently. In spite also of forced feeding she became more and more emaciated. The thyroid tabloids were continued for a week, but as the tetany disappeared maltine and other tonics were substituted. At this time it was thought that the symptoms of insufficiency of thyroid secretion were due to the inability of the remaining piece of thyroid gland to supply sufficient secretion for the needs of the organism for the first few days after the operation-that is, until it had become accustomed to the extra work thrown upon it by the removal of the rest of the gland-and that coincident with the disappearance of the tetany and the absence of other symptoms of insufficiency it had then taken orer its new duties and was now supplying all the secretion that was necessary. However, on the twelfth day the tetany returned and the tabloids were again exhibited but with little or no effect; for, though the spasms were not so frequent, they were more severe than before and were confined mainly to the extremities but with occasional respiratory seizures. The patient was bathed in perspiration after the attacks and the emaciation and general weakness became more and more marked. Finally, 24 days after the operation she died after a very severe and almost general seizure which particularly involved the respiratory muscles.

The cause of death was post-operative tetany of the respiratory muscles. This tetany in the early stage resembled hysteria and were it not for the attendant circumstances of the case it might easily have been mistaken for it; while later the spasms became so severe as to simulate tetanus. At the post-mortem examination no trace of thyroid substance could be found in the neck and it was quite obvious that the B B 2 
small piece that had been left at the operation had undergone complete atrophy. No lesions were found in any other organ. It is to be regretted that thyroid medication was not pushed to the extreme limit of safety in this case as it must be confessed that with the present facilities for the introduction of thyroid material into the body post-operative tetany ought to be a curable complication.

CASE 2. - The second case was the exact antithesis of the first and was that of a goitre of eight years' standing in a blind man, aged 24 years. As the illustration shows (Fig. 2)

FIG. 2.

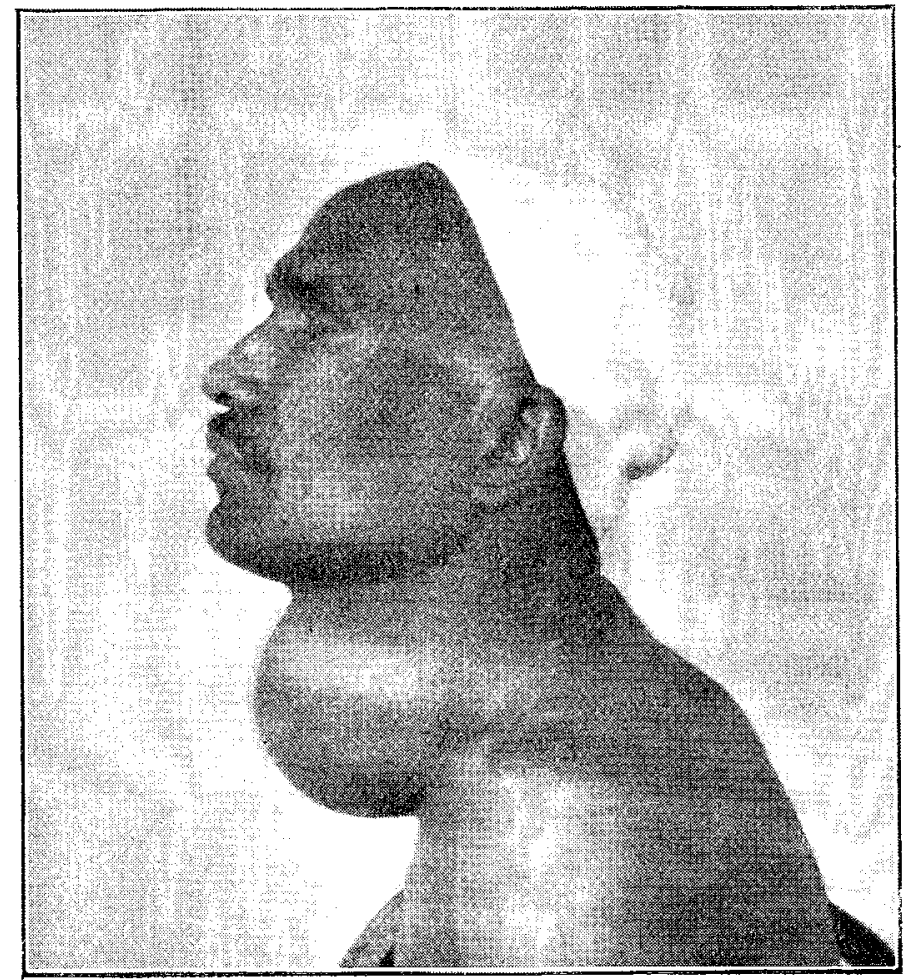

Showing single-lobed goitre.

and as subsequent operation proved, the enlargement was confined entirely to the isthmus. It had increased rapidly in size during the last three years and was producing a certain amount of difficulty in breathing owing to direct pressure upon the trachea.

Removal was effected in the usual way but the operation was rather difficult on account of the extreme vascularity of the mass and its firm attachments above. The only points at which the thyroid substance was divided were at either side, a very narrow pedicle connecting the enlarged isthmus with two normal lateral lobes. The structure of the mass was that of an ordinary parenchymatous goitre with considerable cystic change. Three layers of silk sutures were put in, one for the deep cervical fascia, another to draw the edges of the sterno-thyroid and sterno-hyoid muscles together in the middle line, and the third for the edges of the skin flap. A packing of sterilised gauze was placed in the cavity deep to the cervical fascia, the end being brought out of the lower end of the flap. The operation took about an hour and the patient was rather collapsed after it though not a great deal of blood had been lost. Almost as soon as the effects of the anæsthetic wore off he began to be restless and excited and both his pulse and respiration became very rapid. $\mathrm{He}$ was given normal saline solution by the rectum and strychnine and morphia hypodermically but without much effect, for the same evening his pulse was 144 , his respirations were 52 , and his temperature was $102^{\circ} \mathrm{F}$. No physical signs either in the heart or the lungs could be found to account for these symptoms and Mr. Ll. P. Phillios, the resident surgical officer of the Kasr-el-Aini Hospital, regarding the case as one of thyroid toxæmia very rightly removed the packing and washed out the whole cavity with saline solution and then put in a large drainage-tube. The patient's condition did not appreciably improve during the night and next morning he was drowsy and semi-conscious and the temperature reached $103^{\circ}$, while the pulse and the respira. tion maintained their former rapid rate. He was then transfused by the veins with one and a half litres of normal saline solution and the wound was freely opened up and well irrigated. All to no purpose, however, for, although the restlessness was controlled by morphia, his general condition did not improve and he died 28 hours after the operation.

No post-mortem examination was allowed but it seems reasonable to conclude that the cause of death was the sudden introduction of thyroid secretion into the system, absorption taking place from the cut surfaces of the isthmus, the extreme vascularity of the part accounting for the rapidity of absorption. The symptoms were not those of collapse but were exactly similar to those observed when the administration of thyroid extract has been pushed to a severe degree. In a fairly large series of cases of partial thyroidectomy I have never met with either of these complications before and they illustrate very well the opposite extremes of the possible dangers due to interference with the structure upon which we are operating.

My only other fatalities have been one case from hæmorrhage, eight hours after operation-due entirely to the neglect of a native attendant-and another from a condition which I may call " kismet" and which it will be difficult for those who work entirely among Europeans to understand. The patient was an old woman who, three weeks after the operation and when she was ready to leave hospital, refused to go out as she had no home to go to and announced her intention to die, which she did in spite of all efforts to keep her alive by food, strychnine, and stimulants. She gradually "faded away" and nothing was found post mortem to justify her dying. I have met with this "death by willing" on other occasions in hospital practice in Egypt. These cases cannot be included in the category of those in whom "the operation was a perfect success but the patient died," for neither the operation nor the condition that necessitated it was in any way responsible for the death. They were typical instances of the power of dying at will.

Cairo.

\section{ON THE DANGER OF RAILWAY TRIPS TO HIGH ALTITUDES, ESPECIALLY FOR ELDERLY PEOPLE. ${ }^{1}$}

BY THEODORE ZANGGER, M.D., LATE ASSISTANT PHYSICIAN, UNIVERSITY HOSPITAL, ZÜRICH.

OuR Alps claim their annual victims. Not only thoughtless youths but careful men who have arrived at the age of discretion succumb to accidents of various kinds, so that the deaths from such causes, often in themselves avoidable, amount to 60 per annum. Nay, even sober-minded greyhaired men who have many years since dismissed any thought of Alpine climbing, and who rightly condemn those who hazard their limbs or even their lives by undertaking difficult ascents without guides,-even these may inadvertently run great risks, as will presently be shown. The great majority of the public, and even some medical men, ignore the various dangers that menace the lives of elderly persons undertaking mountain ascents-say, at elevations higher than 3300 feet above sea-level. These dangers may be summed up in two words, apoplexy and heart failure ; but instead of the latter expression it is better to use the two medical terms "thrombosis of the heart" and "embolus of the lung." The explanation of the matter is extremely simple. On the one hand, many persons have a difficulty in realising that they are getting on in years, while, on the other hand, degenerative processes may develop in the heart without causing any symptoms, and in the case of such patients incautious mountain ascents are not only dangerous to life but may even have a fatal termination. I wish to call particular attention to the circumstance that such seizures do not occur exclusively during the stay of the patients at the high altitude but may come on, either slowly or abruptly, one, two, and even three days after they have returned to the low ground. The general public, and sometimes also the medical profession, therefore fail to perceive that there is a direct connexion between the catastrophe and the high altitude. Not a few medical men are of opinion that there cannot be any such causal connexion when several days intervene between the stay at the high altitude and the onset of heart failure or apoplexy, but they are certainly in error, though I quite recognise the great difficulty

1 Abstract of a paper read before the Medical Society of Zürich on Nov. 15th, 1902 . 